\title{
Organic Acid Metabolism and the Impact of Fermentation Practices on Wine Acidity - A Review
}

\author{
B.S. Chidi, F.F. Bauer, D. Rossouw* \\ Institute for Wine Biotechnology, Department of Oenology and Viticulture, Stellenbosch University, Private Bag X1, 7602 \\ Matieland (Stellenbosch), South Africa
}

Submitted for publication: February 2018

Accepted for publication: May 2018

Keywords: Fermentation, wine yeast, organic acid, metabolism, Saccharomyces cerevisiae

The conversion of grape sugar to ethanol and carbon dioxide is the primary biochemical reaction in alcoholic wine fermentation, but microbial interactions, as well as complex secondary metabolic reactions, are equally relevant in terms of the composition of the final wine produced. The chemical composition of a wine determines the taste, flavour and aroma of the product, and is determined by many factors such as grape variety, geographical and viticultural conditions, microbial ecology of the grapes and of the fermentation processes, and the winemaking practices. Through the years, major advances have been made in understanding the biochemistry, ecology, physiology and molecular biology of the various yeast strains involved in wine production, and how these yeasts affect wine chemistry and wine sensory properties. However, many important aspects of the impact of yeast on specific wine-relevant sensory parameters remain little understood. One of these areas of limited knowledge is the contribution of individual wine yeast strains to the total organic acid profile of wine. Wine quality is indeed very directly linked to what wine tasters frequently refer to as the sugar-acid balance. The total acidity of a wine is therefore of prime sensory importance, and acidity adjustments are a frequent and legal practice in many wineries. However, the total acidity is the result of the sum of all the individual organic acids that are present in wine. Importantly, each of these acids has its own sensory attributes, with descriptors ranging from fresh to sour to metallic. It is therefore important not only to consider total acidity, but also the contribution of each individual acid to the overall acid profile of the wine. This review will summarise the current knowledge about the origin, synthesis and analysis of organic acids in wine, as well as on the management of wine acidity.

\section{INTRODUCTION}

Organic acids and total acidity play a pivotal role in wine sensory perception, and directly influence the overall organoleptic character of wines. It is generally acknowledged that too much acidity will taste excessively sour and sharp, while wines with too little acidity will taste flabby and flat and present a less-defined flavour profile (Mato et al., 2005). Desirable acidity is also a function of wine sweetness, which is mostly, but not uniquely, derived from residual grape sugars. Sweeter wines usually require higher levels of acidity to be considered of good sensory quality (Schmit et al., 2013). Organic acid concentrations in grape musts are primarily a function of grape maturity and variety (Conde et al., 2007). Alcoholic fermentation, however, change the concentration and content of wine acidity, and may result in a higher or lower total acidity of the wines (Volschenk et al., 2006; Yabaya et al., 2016). Importantly, different organic acids have different organoleptic properties, and the impact of organic acids is therefore not only linked to total acidity and $\mathrm{pH}$, but to the specific concentration of each acid in the wine.

In general, malic, citric and tartaric acids are the primary acids in wine grapes, and these acids also contribute the highest proportion of acidity (known as titratable acidity) to the final wine (Defilippi et al., 2009). However, during alcoholic fermentation, several other important organic acids, such as succinic, pyruvic, lactic and acetic acid, are produced by yeast and bacteria and are mainly associated with the fresh, tart, sour and sometimes metallic taste of wines (Usseglio-Tomasset, 1995; Margalit, 1997; Bely et al., 2003). These acids have also been found to contribute to the stability of wines, especially white wines (Tita et al., 2006; Kučerová \& Široký, 2014). Moreover, depending on the requirements for acid balance and maintenance, as well as the winemaking practices of some wines, acids such as ascorbic, sorbic and sulphurous acids are also used during winemaking.

*Corresponding author: E-mail address: debra@sun.ac.za [Tel.: +2721 808 4346; Fax: +2721 80837711$]$ 
As grapes ripen, their sugar concentrations generally increase while their acidity declines. It has been shown that grapes from cooler wine regions generally have higher levels of acidity, which is attributed to slower grape ripening compared to grapes from warmer climate areas (Schmit et al., 2013). It has also been reported that lower acidity levels in white wine are often the cause of the polymerisation of phenolic compounds, resulting in brown deposits and therefore causing darkening of white wine (Darias-Martín et al., 2000). On the other side of the acidity spectrum, general concerns about undesirably high levels of acidity are common in oenology, and in some cases winemakers can resort to malolactic fermentation as a way to reduce wine acidity (López et al., 2008). Although malolactic fermentation is considered the most natural method for the adjustment of wine acidity, microbial stability and organoleptic complexity, there are a number of concerns, such as spoilage (especially in warm viticultural regions with grapes containing less malic acid) and undesirable changes in wine flavour associated with the metabolic activity of lactic acid bacteria, which makes this technique inappropriate for certain types of wine (Bauer \& Dicks, 2005).

Acidity is a primary driver of important management decisions related to contamination risks and sensorial properties (Akin et al., 2008). In terms of contamination risks, it is well known that lower acidity and higher $\mathrm{pH}$ generally support the growth of microorganisms, including several unwanted or spoilage species (Bisson \& Walker, 2015). Wines with a high $\mathrm{pH}$ therefore usually require more careful microbiological management, including the use of larger amounts of $\mathrm{SO}_{2}$. Acidity and $\mathrm{pH}$ are also central features of the sensorial properties of wine, although $\mathrm{pH}$ and acid taste are not always directly correlated. For this reason, the adjustment of acid in grape must is a critical part of winemaking. Under conditions of normal alcoholic fermentation, the titratable acidity (TA) of wine increases by 1 to $2 \mathrm{~g} / \mathrm{L}$ from the start to the finish of alcoholic fermentation as a result of the evolution of acids such as succinic, acetic, lactic, malic and pyruvic acids (Volschenk et al., 2006). While it is essential to monitor $\mathrm{pH}$ and acidity throughout fermentation, acid management includes the addition of acids, mostly tartaric acid, to grape must with a high $\mathrm{pH}$ (Petrie \& Sadras, 2007). This practice is of particular importance in warm viticultural regions, where tartaric acid is most commonly added at the start of alcoholic fermentation in order to prevent the proliferation of spoilage LAB and other bacteria during alcoholic fermentation (Volschenk et al., 2006). Several methods have been established for identifying and quantifying organic acids in grape juice and wine. Such methods include non-enzymatic and enzymatic spectrophotometric, chromatographic and electrophoretic methods (Mato et al., 2005). However, high performance liquid chromatography (Castellari et al., 2000; Pereira et al., 2010; Park et al., 2017), ion chromatography (Kupina et al., 1991), gas chromatography (West \& Mauer, 2011; Pinu \& Villas-Boas, 2017) and capillary zone electrophoresis (Kandl \& Kupina, 1999; Cortacero et al., 2005; Mato et al., 2006) are the preferred methods for organic acid analysis.

Acid control and regulation in wine is therefore regarded as a key process for winemakers to control wine character and quality, combining controlled $\mathrm{pH}$ adjustments and informed yeast selection and management. However, the impact of many other environmental and nutritional management practices that may modulate yeast organic acid metabolism during the winemaking process, and thus final wine acidity, have not yet been fully elucidated.

\section{Wine organic acids}

Organic acids in wine derive either directly from the grape, or are the result of microbiological activities that take place before, during or after alcoholic and malolactic fermentation. While the most commonly measured feature of wine acidity is the total acidity (TA) and $\mathrm{pH}$, some organic acids are important markers for fermentation management and wine flavour and aroma. Malic acid is monitored to measure the progress of malolactic fermentation, acetic acid is monitored as an indicator of fermentation problems or of spoilage, and citric acid may be added to adjust acidity and chelate metal ions to prevent nutrients from precipitation resulting from the interaction of nutrients with metal ions, such as iron precipitating with phosphorus (Fowles, 1992).

\section{Wine organic acids derived from grapes Tartaric acid}

Unlike most other fruits, grapes contain significant amounts of tartaric acid. It is regarded as the main contributor to wine acidity, and presents a tart taste in wine (Volschenk et al., 2006). Tartaric acid is not metabolised by grape berry cells via respiration in the same manner as malic acid, and the level of tartaric acid in the grapes remains relatively consistent throughout the ripening process. The concentration of tartaric acid in grapes depends largely on the grape variety and soil composition of the vineyard. Levels usually range from 4.5 to $10 \mathrm{~g} / \mathrm{L}$ at the end of the grape's vegetative growth phase (Ribéreau-Gayon et al., 2006). In cold climates, concentrations of above $6 \mathrm{~g} / \mathrm{L}$ are commonly reached, while low levels of 2 to $4 \mathrm{~g} / \mathrm{L}$ are more commonly observed in warm climates (Apichai et al., 2007). Because of its stability, and the fact that yeast and other microorganisms are unable to metabolise tartaric acid, it is the acid that is most commonly employed for $\mathrm{pH}$ adjustment in the wine industry (Volschenk et al., 2006).

\footnotetext{
Malic acid

L-malic acid is commonly found in many fruits, including green apples and grapes (Krueger, 2012). Mature grapes contain between 2 and $6.5 \mathrm{~g} / \mathrm{L}$ of L-malic acid (RibéreauGayon et al., 2000). Excessive amounts of malic acid (15 to $16 \mathrm{~g} / \mathrm{L}$ ) may be present in grapes harvested from exceptionally cool climatic regions (Gallander, 1977). The highest concentration of malic acid attained depends on the grape variety, with some, such as Barbera, Carignan and Sylvaner, being naturally prone to higher malic acid levels. Before the change in colour of grapes at véraison, the malic acid content can reach up to $25 \mathrm{~g} / \mathrm{L}$, before declining to 2 to $6.5 \mathrm{~g} / \mathrm{L}$ by maturation (Ribéreau-Gayon et al., 2000). When malic acid levels are too high, wines may taste sour and may require the use of lactic acid bacteria to convert malic acid to the less harsh and softer lactic acid. The induction of malolactic fermentation is beneficial to some wines,
} 
but in white wines, such as Chenin blanc, it may result in the production of off-flavours such as diacetyl (Bartowsky $\&$ Henschke, 2004). Nevertheless, the use of alternative technologies to develop malolactic fermentation in wine is now a priority (Maicas, 2001; Betteridge et al., 2015; Lerena et al., 2016; Lucio et al., 2017).

\section{Citric acid}

Citric acid is an intermediate of the TCA cycle and is widespread in nature (e.g. in lemons). It plays a critical role in the biochemical processes of grape berry cells, bacteria and yeast. High citric acid levels during fermentation could lead to a slower yeast growth rate (Nielsen \& Arneborg, 2007). However, concentrations of citric acid in must and wine prior to malolactic fermentation are usually relatively low, between 0.5 and $1 \mathrm{~g} / \mathrm{L}$ (Kalathenos et al., 1995). Citric acid addition during fermentation influences the acidity and flavour of wines by promoting the perception of "freshness", while, at the same time, promoting microbial instability and the growth of unwanted microorganisms.

\section{Organic acids derived from fermentation Succinic acid}

Succinic acid occurs widely in nature in both plants and animals. Succinic acid levels vary between grape varieties, as concentrations are usually very low in white cultivars but slightly higher in red grapes. Succinic acid is one of the most important acids that develop during fermentation due to yeast metabolism, with concentrations averaging approximately 0.5 to $1.5 \mathrm{~g} / \mathrm{L}$ in wine. It is a dicarboxylic acid produced mainly as an intermediate of the tricarboxylic acid (TCA) cycle during aerobic respiration, but is also one of the fermentation end products of anaerobic metabolism. Songa and Lee (2006) reported that the organic acid responsible for the largest part of the increase in titratable acidity during fermentation is succinic acid. Bertolini et al. (1996) previously reported the same observations, with succinic acid accounting for $50 \%(1.23 \mathrm{~g} / \mathrm{L})$ of the observed increase in wine acidity. In general, it is expected that, during fermentation, the formation of non-volatile organic acids ranges from 1 to $4 \mathrm{~g} / \mathrm{L}$, but such ranges vary significantly with different fermentation conditions (Lamikanra, 1997). The organoleptic character of succinic acid has been described as sour with a salty, bitter taste, and its threshold concentration is approximately $35 \mathrm{mg} / \mathrm{L}$ (Benito et al., 1999). Because of its bitter-salty flavour, winemakers pay particular attention to succinic acid levels in wine. Although succinic acid is relatively resistant to microbial utilisation under fermentative conditions, it cannot be used as an acidulating agent due to this bitter-salty taste attribute (Ribéreau-Gayon et al., 2006).

\section{Lactic acid}

Lactic acid is an organic acid that also contributes to the overall acidity of wine. The reason why it is attractive to winemakers is that it is much softer on the palate than malic acid (Robinson, 2006). Lactic acid concentrations normally average from 1 to $3 \mathrm{~g} / \mathrm{L}$ in wines (Boulton et al., 1996), but can be higher in wines that have undergone malolactic fermentation, whereby malic acid is decarboxylated to lactic acid (Volschenk et al., 2006). Unlike malic and tartaric acid, lactic acid is a softer and milder acid that contributes to a creamier mouthfeel of the wine. During winemaking, lactic acid production is usually controlled by sulphur dioxide addition, which suppresses the metabolic activities of lactic acid bacteria such as those belonging to the Oenococcus and Lactobacillus genera (Osborne et al., 2000). However, small amounts of lactic acid can also be synthesised through cellar practices such as maceration and cold stabilisation (Jackson \& Schuster, 1997). While high lactic acid levels present no major problems in wine, lactic acid bacteria are capable of changing the sensorial characteristics of certain wines through the degradation of terpenes and other flavour molecules produced during alcoholic fermentation, as well as producing potentially undesirable aromatic compounds such as diacetyl (Lonvaud-Funel, 1999).

\section{Acetic acid}

Acetic acid is a two-carbon volatile organic acid produced during wine fermentation and is mostly responsible for the sour and vinegary smell and taste in wines. Alcoholic fermentation of grapes usually results in the production of acetic acid. This process occurs mainly at the beginning of alcoholic fermentation, and again towards the end (Bartowsky et al., 2003). Apart from yeast metabolic activity, the involvement of aerobic acetic acid bacteria during fermentation can also produce acetic acid by oxidising ethanol (Pronk et al., 1996; Ghosh et al., 2012).

In $S$. cerevisiae, a direct relationship has been established between glycerol and acetic acid production during fermentation (Remize et al., 1999, Erasmus et al., 2004; Goold et al. 2017). S. cerevisiae continuously has to equilibrate redox imbalances, which are a feature of alcoholic fermentation. Indeed, anabolic reactions related to biomass formation divert glycolytic intermediates away from ethanol production, requiring other pathways for the regeneration of $\mathrm{NAD}^{+}$, which is required to maintain flux through glycolysis. $\mathrm{NAD}^{+}$is therefore regenerated through glycerol biosynthesis. However, excess production of $\mathrm{NAD}^{+}$ may occur, which is balanced through the production of acetic acid from acetaldehyde, a reaction that works as a redox sink to convert NAD ${ }^{+}$to NADH (Michnick et al., 1997; Remize et al., 1999). Wine yeasts therefore also produce acetic acid in response to hyperosmotic stress conditions. The primary response to such conditions is indeed the production of glycerol to act as a compatible compound (Hohmann, 2002). As a consequence, the redox balance is disturbed, since $\mathrm{NADH}$ is oxidised to NAD, leading to acetic acid production to regenerate $\mathrm{NADH}$. Such hyperosmotic conditions tend to prevail at yeast inoculation at the start of alcoholic fermentation due to the high initial sugar concentrations (Erasmus et al., 2004).

The critical acetic acid detection threshold in wine is estimated to be approximately $600 \mathrm{mg} / \mathrm{L}$. However, the normal desirable acetic acid level in wines is about 100 to $300 \mathrm{mg} / \mathrm{L}$ (Ribéreau-Gayon et al., 2006). High volatile acidity in wine presents a major problem, with most wineries recommending the use of lower initial sugar-containing must to reduce acetic acid formation during fermentation. However, acetic acid concentrations can reach above $1 \mathrm{~g} / \mathrm{L}$, 
depending on environmental factors and the nutritional composition of the must, as well as the influence of spoilage yeasts and bacteria (Bely et al., 2003). Since the aroma threshold for acetic acid varies depending on the wine variety and style, its maximum acceptable limit for most wines is $1.2 \mathrm{~g} / \mathrm{L}(\mathrm{OIV}, 2010)$. However, the volatile acidity of ice wines and botrytised wines can reach a maximum acetic acid concentration of $2.1 \mathrm{~g} / \mathrm{L}(\mathrm{OIV}, 2010)$.

\section{Pyruvic acid}

Pyruvic acid is generally present in wine as a secondary product of alcoholic fermentation, and the amount of pyruvic acid in wine varies considerably. Concentrations of pyruvic acid average from anywhere between 10 to $500 \mathrm{mg} / \mathrm{L}$ in dry wines (Usseglio-Tomasset, 1995). In terms of its sensory attributes, this acid imparts a slightly sour taste. It is formed at the onset of fermentation and decreases towards the end of fermentation (Usseglio-Tomasset, 1995). It also plays an indirect role in wine quality due to its ability to bind sulphur dioxide. $\mathrm{SO}_{2}$ is widely used in winemaking, and its germicidal effect is hugely dependent on the levels of free sulphur dioxide. Free $\mathrm{SO}_{2}$ is indeed the most antimicrobial form of $\mathrm{SO}_{2}$, and bound $\mathrm{SO}_{2}$ has much weaker antimicrobial properties (Fugelsang \& Edwards, 2007; Pezley, 2015). Binding of $\mathrm{SO}_{2}$ by pyruvic acid thus enables the growth of bacteria such as those involved in malolactic fermentation (Wells \& Osborne, 2012). Any compound which binds sulphur dioxide reduces its effectiveness, and pyruvic acid is second only to acetaldehyde in this regard.

\section{Yeast metabolism}

\section{Yeast central carbon metabolism}

Most yeast species have similar central carbon metabolic pathways, but differences in nutrient uptake and utilisation, as well as in the regulation of fermentation and respiration, have been noted (Flores et al., 2000; Conrad et al., 2014). Few yeast species are capable of growing under close-toanaerobic conditions as successfully as $S$. cerevisiae (Visser et al., 1990; Moller et al., 2001). Therefore, the physiology of this organism during fermentative, respiratory and respiro-fermentative conditions has attracted considerable research interest. This interest is mainly driven by the industrial significance of this species, and is linked to its ability to produce ethanol, proteins, cell biomass and other commercially relevant products (Khan \& Dwivedi, 2013). The metabolism of yeast, as of all living cells, is interconnected through the coupling of anabolic and catabolic pathways. As summarised in Fig. 1, ATP is provided by the oxidation of organic carbon sources, yielding energy, ethanol, carbon dioxide and various intermediate metabolites such as organic acids (Rodrigues et al., 2006).

\section{Glycolysis}

The principal source of energy production in S. cerevisiae is hexoses, primarily glucose, and the conversion of such hexoses to pyruvate is achieved via the glycolytic pathway (Fernie et al., 2004). Glycolysis provides the yeast with energy, together with essential glycolytic intermediates under both aerobic and anaerobic conditions. Under aerobic conditions, the pyruvate formed by glycolysis enters the TCA

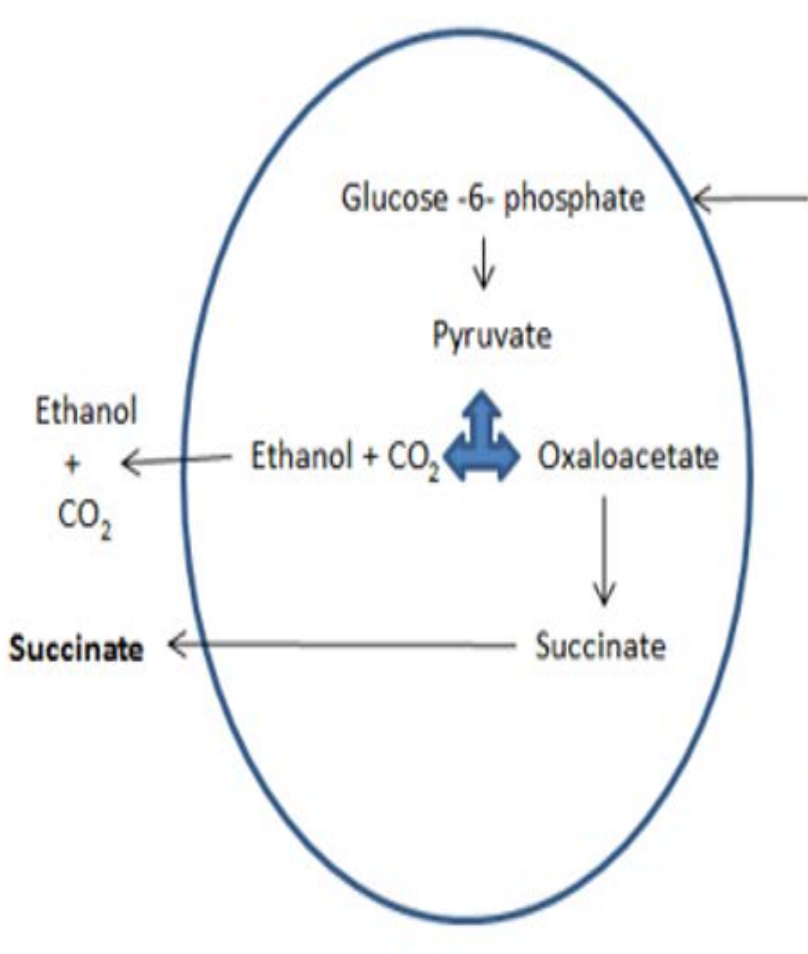

Anaerobic fermentation

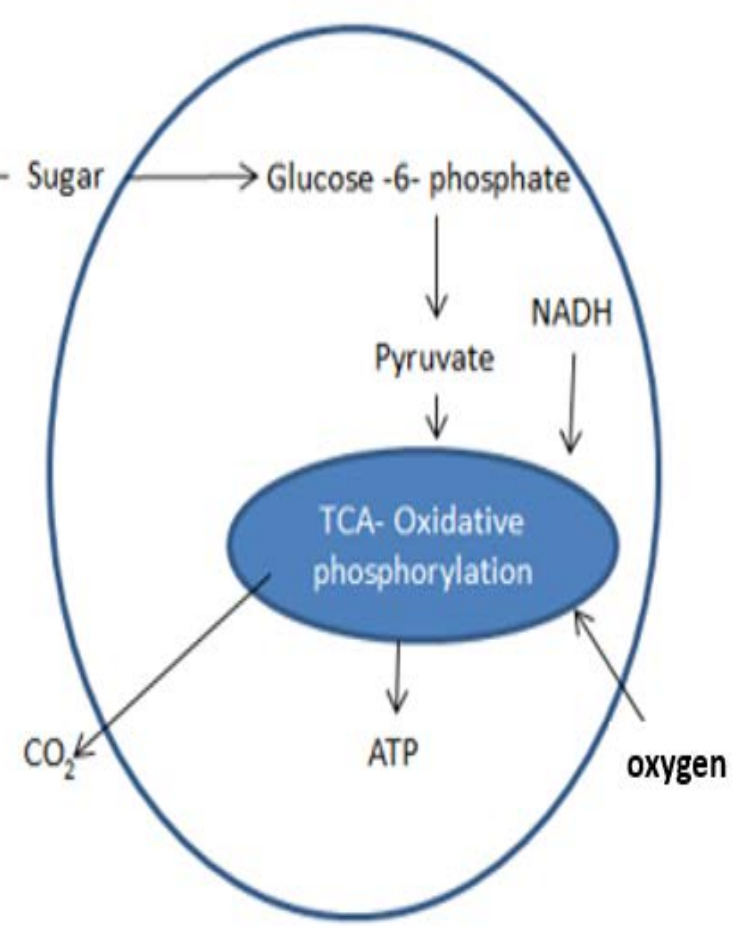

Aerobic fermentation

FIGURE 1

Summary of major sugar catabolic pathways in S. cerevisiae under aerobic versus anaerobic conditions. 
cycle and energy is subsequently generated by substratelevel phosphorylation in the presence of oxygen.

However, sugar dissimilation during the anaerobic growth of yeast occurs via alcoholic fermentation that enables the reoxidation of the NADH formed during glycolysis. Moreover, the reduction of the glycolytic dihydroxyacetone phosphate to glycerol-3-phosphate during glycolysis (in the production of glycerol) is also essential to re-oxidise the NADH formed by sugar catabolism under anaerobic conditions. Re-oxidation of NADH provides $\mathrm{NAD}^{+}$, which enables the continuation of glycolysis in the absence of oxygen (and thus without a final electron acceptor). The redox balance is thus maintained by both ethanol and glycerol formation (Rigoulet et al., 2004; Navarrete et al., 2014). The glycolytic pathway is also responsible for pyruvate production. Pyruvate is a key metabolite not only in energy generation, but also as an intermediate in many other yeast metabolic pathways, including anabolic pathways involved in biomass formation (Zhu et al., 2008). Besides its role in cellular metabolism, it is also an important organic acid, which contributes to the overall acid balance and organoleptic properties of wine.

\section{Glyoxylate pathway}

Another pathway responsible for the replenishment of TCA intermediates such as oxaloacetate and a-ketoglutarate is referred to as the glyoxylate cycle (Fig. 2), which is most active when yeast oxidises acetate (Lee et al., 2011). This pathway is essential for the continuous flow of carbon through the TCA cycle (Servi, 1990), because when intermediates of the TCA cycle are withdrawn for anabolic reactions, the cycle is replenished by the glyoxylate cycle (Wendisch et al., 2006). The enzymes of the TCA cycle and the glyoxylate cycle are physically segregated, with the glyoxylate cycle enzymes of yeast and fungi localised in a specialised organelle called the glyoxysome/peroxisome (Donnelly et al., 1998). Glyoxysomes import fatty acids and aspartate, which present acetyl-CoA to the shunt. During this process, aspartate transaminase converts aspartate into oxaloacetate, permitting the incorporation of acetyl CoA into citrate via citrate synthase (Pronk et al., 1996). However, the maintenance of the glyoxylate pathway is mostly controlled by the oxidation of succinate to oxaloacetate, which can be converted back to aspartate by aspartate transminase (Popov et al., 2005). When the glyoxylate pathway is active, it bypasses some reactions of the TCA cycle in which $\mathrm{CO}_{2}$ is released, thus conserving four-carbon compounds responsible for the further biosynthesis of other metabolites, such as organic acids. (Songa \& Lee, 2006). While this pathways is fully active primarily under respiratory conditions, parts of it play important roles during fermentation and act as a source of organic acids, such as succinic acid (Heerde \& Radler, 1978).

\section{TCA cycle}

The tricaboxylic acid (TCA) cycle is directly involved in the formation of most intermediate carboxylic acids, including succinic acid. Under aerobic conditions, the main function of the TCA cycle is the reduction of the coenzymes that are necessary for the full operation of the respiratory electron transport chain (Fernie et al., 2004). Its role in anaerobic conditions was understated in the past, but proof of the TCA cycle's importance in anaerobic fermentation was provided by showing that all of its enzymes are present within anaerobically grown yeast cells (Kuyper et al., 2004). Under

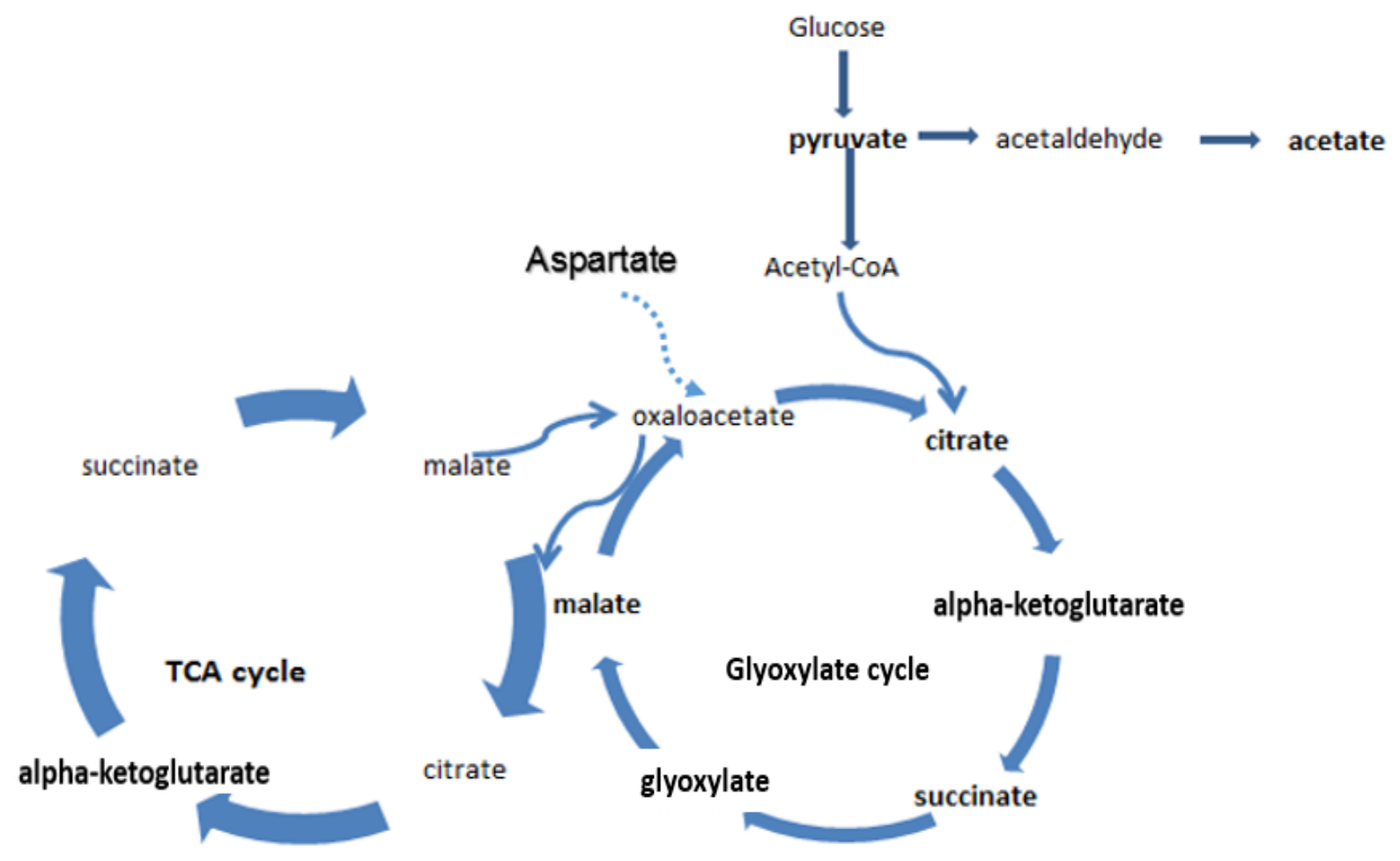

FIGURE 2

A simplified pathway diagram showing yeast-derived acids and their connection to the TCA and glyoxylate cycles. 
anaerobic conditions, however, the TCA pathway more frequently operates in a branched manner, with a reductive arm working in the reverse direction of the normal cycle and leading to the formation of succinate, and an oxidative arm leading to the formation of $\alpha$-ketoglutarate (Tu et al., 2005).

The TCA cycle is in large part responsible for citrate, malate and succinate production (Heerde \& Radler 1978; Albers et al., 1996). While citric acid and malic acid depend mostly on TCA cycle reactions, succinic acid can be formed in yeast via four main pathways, including amino acid catabolism, depending on the growth conditions and the availability of nitrogen sources in the culture media (Cartledge, 1987; Finley et al., 2012). Under fermentative conditions, the TCA cycle operates in a branched manner, with a reductive branch leading to succinate formation and the oxidative branch leading to $\alpha$-ketoglutarate. However, the flux through these pathways depends on nitrogen availability, since $\alpha$-ketoglutarate is the primary ammoniumfixing compound. The reductive branch of the TCA cycle is the principle metabolic pathway for succinate formation under anaerobic conditions, particularly in the absence of glutamate. In contrast, glutamate is responsible for the production of succinate via the oxidative arm of the TCA cycle. Pyruvate and aspartate also play an important role in the formation of succinic acid via the reductive branch of the cycle, or from pyruvate via the oxidative branch.

\section{Nitrogen metabolism as another source of organic acids}

Nitrogen availability has a noteworthy (although indirect) impact on organic acids formed via the TCA cycle. For instance, glutamate (a preferred amino acid) can lead to the production of succinic acid via the deamination of glutamate to a-ketoglutarate (Sanborn et al., 1979) (Fig. 3). In a study by Alberts et al. (1994), the assimilation of $3-{ }^{13} \mathrm{C}$ glutamate led to significant succinate concentrations that were labelled at the second and third carbon positions. The results prove that $3-{ }^{13} \mathrm{C}$ glutamate was deaminated to $3-{ }^{13} \mathrm{C}$ a-ketoglutarate, which was then oxidatively decarboxylated to succinyl CoA and succinate. In their observations, Alberts et al. (1994) found that $17 \%$ of the carbon from glutamate was converted to succinate, which further supports succinate synthesis from glutamate. When glutamate is used as a nitrogen source, the reduced synthesis of 2-oxoglutarate from glucose causes fewer reducing equivalents to be formed, which often reduces the production of glycerol and ethanol (Camarasa et al., 2003). Consequently, a metabolic flux (shift) towards organic acid synthesis might occur.

\section{Acetic acid metabolism}

The yeast biochemical pathways, as well as the individual enzymatic reactions, involved in acetic acid formation during fermentation are reasonably well characterised (Jost \& Piendl, 1975). They include (1) the reversible formation from acetyl Co-A and acetyl adenylate through acetyl Co-A synthetase; (2) the cleavage of citrate by citrate lyase; (3) the production of pyruvate by pyruvate dehydrogenase (PDH), yielding acetyl Co-A, which can be hydrolysed into acetate through acetyl Co-A hydrolase; (4) the reversible formation of acetyl-phosphate by acetyl kinase; (5) and the oxidation of acetaldehyde by aldehyde dehydrogenase (Boulton et al.,
1996; Ribéreau-Gayon et al., 2006). In wine, acetic acid production is mainly due to the latter enzymatic oxidation of acetaldehyde to acetate by acetaldehyde dehydrogenases (Remize et al., 2000).

Under fermentative conditions, acetic acid production is also linked to glycerol formation via redox balancing (Remize et al., 1999; Eglinton et al., 2002; Goold et al. 2017). Glycerol is formed in order to reoxidise the NADH formed during glycolysis (Jackson, 2008), and S. cerevisiae may convert $\mathrm{NAD}^{+}$back to $\mathrm{NADH}$ through acetic acid production. Alterations in glycerol metabolism, such as increased glycerol production, are generally accompanied by an increase in acetic acid production to compensate for changes in the cellular redox balance (De Barros Lopes et al., 2000; Prior et al., 2000; Goold et al., 2017).

\section{Factors affecting organic acid production in wine}

The sensor systems of the yeast cell act to identify variations in environmental conditions (osmolarity, temperature, $\mathrm{pH}$, nitrogen and carbon starvation, chemical and physical agents, etc.). The responses to the sensing of changes in conditions are set in motion by a series of signal transduction pathways, which result in changes to gene expression networks, synthesis of protective molecules and/or modulation of protein activity by post-translational modifications or sub-cellular localisation (Estruch, 2000). The downstream effects of the regulatory responses to these physiochemical factors will, in most cases, have an impact on the primary and secondary metabolism of the yeast, thus affecting the quality and organoleptic characters of the wines produced. These environmental and compositional factors are thus important focus areas in wine research due to their impact on the attributes and perceived quality of the final product. Several influential wine-relevant environmental and nutritional factors that require extensive investigation, as indicated in the current review, include temperature, aeration, $\mathrm{pH}$, nitrogen levels, osmotic stress and vitamins. Furthermore, the effect of individual strains with different genetic backgrounds on organic acid production is also an important area to consider.

\section{Effect of pH on organic acid production by yeast}

The large majority of wines have $\mathrm{pH}$ values between 3 and 4. As with sugars, the $\mathrm{pH}$ level will vary according to the ripeness of the grapes, with increasing ripeness leading to lower acidity and increased $\mathrm{pH}$. For white wines, winemakers often recommend $\mathrm{pH}$ levels between 3.1 and 3.2, and if the $\mathrm{pH}$ is too high $(>\mathrm{pH} 3.4)$, it may be a sign that the grapes are overripe. It is generally known that the activity of enzymes involved in central carbon metabolism is $\mathrm{pH}$ sensitive, which could account for the $\mathrm{pH}$-related changes in the production levels of several organic acids in wine (Agarwal et al., 2007). For this reason, the mono-factorial impacts of $\mathrm{pH}$ on organic acid production have been studied, and several authors have presented significant variation effects of $\mathrm{pH}$ on yeast and bacterial strains in terms of organic acid profiles. The impact of $\mathrm{pH}$ on organic acid productivity is often related to the specific strain employed, which may account for the different trends observed in different studies. For example, high succinic acid levels have been linked to an increased 


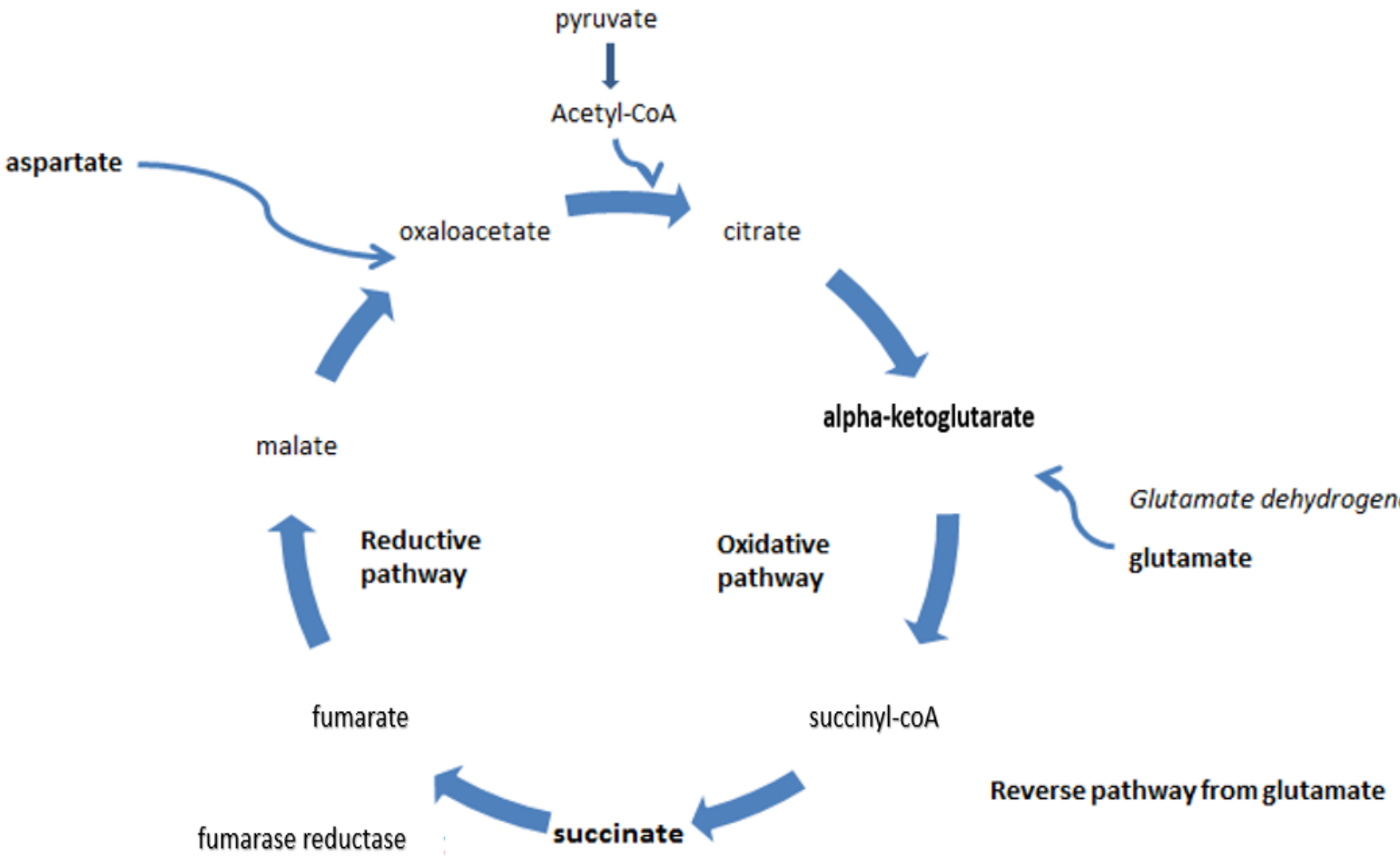

FIGURE 3

Summary of the main pathways involved in succinic acid production/utilisation during anaerobic fermentation.

initial fermentation $\mathrm{pH}$ (Thoukis et al., 1965). The authors observed a slight increase in succinic acid by S. cerevisiae when the grape must was adjusted to $\mathrm{pH}$ values ranging from 3.0 to 3.8 , but more when it was raised from 3.8 to 4.8. The study also indicated a strong direct relationship between glycerol and succinic acid formation at a higher initial $\mathrm{pH}$ of the must. Recently, Liu et al. (2015) reported that lower initial $\mathrm{pH}$ (2.75) showed properties of prolonged yeast lag phase, increased acetic acid levels, and decreased final content of succinic acid when three $S$. cerevisiae strains were tested under winemaking conditions. Several authors have also noted a significant increase in pyruvic acid levels when fermentation $\mathrm{pH}$ was increased (Graham et al., 1979). Rankine (1967) also showed that yeast strain variability and $\mathrm{pH}$ appeared to be the two most influential factors affecting the pyruvic acid content of wines. In this study, however, pyruvic acid production only showed $\mathrm{pH}$-dependent trends for some of the strains evaluated.

\section{Effect of aeration on organic acid production by yeast}

The fermenting must is easily saturated in oxygen (6 to $8 \mathrm{mg} / \mathrm{L}$ ) at cellar temperature (Du Toit et al., 2006). Several techniques are available to provide at least limited amounts of oxygen during the fermentation process, including pumping-over and micro-oxygenation. Pumping-over is not recommended in white winemaking because of oxidation concerns; however, oxygen can be introduced during the pressing of whole clusters, transfer from tank to tank, filtration, racking, centrifugation, bottling and barrel ageing (Cheynier, 1993). According to Saa et al. (2012), for oxygen solubility in fermentation media at $25^{\circ} \mathrm{C}$ (i.e. about $7 \mathrm{mg} / \mathrm{L}$ ), $15 \%$ oxygen saturation (with air) would be equivalent to around $1 \mathrm{mg} / \mathrm{L}$ of molecular oxygen. Aeration has been shown to play a fundamental role in the production of many secondary metabolites. For example, the level of citric acid production by yeast as well as other fungi was previously shown to be strongly dependent on the oxygen availability in the fermentation vessel (Sakurai et al., 1996). Sufficient oxygen supply is extremely important during citric acid metabolism, since even short interruptions in oxygen supply can result in a complete loss of citric acid formation (Yigitoglu, 1992; Rywińska et al., 2012). Previously, Rehm et al. (1980) indicated that the formation rate of citric acid strongly coincides with the ratio between ATP and ADP at various $\mathrm{pH}$ values. The authors also indicated that the energy generated by substrate-level phosphorylation is used to promote the excretion of organic acids (in particular citric acid) by the $\mathrm{pH}$-dependent active transport system.

In many cases, aeration during fermentation might increase the production of several secondary metabolites, such as succinic, pyruvic and acetic acid. This behaviour has been correlated with the increase in the levels or activity of the TCA enzymes involved in the biosynthesis of these secondary metabolites during aeration, of which succinic acid is an intermediate (Boulton et al., 1996). The synthesis of succinic acid has also previously been tested in apple and grape juices. For instance, when Saccharomyces cerevisiae EC1118 was assessed in white wine fermentations, acetic acid was produced only under conditions of strict anaerobiosis $(0.3 \mathrm{C}-\mathrm{mmol} \mathrm{g} / \mathrm{DW} / \mathrm{h})$. On the other hand, a striking and significant increase in the level of succinic acid production occurred between 1.2 and $2.7 \mu \mathrm{M}$ dissolved oxygen conditions (from 0.02 to $0.27 \mathrm{C}-\mathrm{mmol} \mathrm{g} / \mathrm{DW} / \mathrm{h}$ ) (Aceituno et al., 2012). In another study (Estela-Escalante 
et al., 2012), compounds of sensory importance produced by Saccharomyces cerevisiae RIVE V 15-1-416 cultivated in apple juice at $28^{\circ} \mathrm{C}$ in static and agitated cultivation (200 rpm) were analysed. At the end of fermentation, the authors reported an increase $(0.77 \mathrm{~g} / \mathrm{L}$ under static and $1.32 \mathrm{~g} / \mathrm{L}$ under agitate cultivation) in succinic acid levels under agitated cultivation, whereas acetic acid levels decreased $(51.0 \mathrm{~g} / \mathrm{L}$ under agitated and $266 \mathrm{~g} / \mathrm{L}$ under static cultivation). Recently, oxygenation levels in wine were assayed with $M$. pulcherrima CECT12841 and S. cerevisiae EC1118 containing $10 \%$ or $25 \%$ air (maximum dissolved oxygen levels around 0.7 and $1.7 \mathrm{mg} / \mathrm{L}$ respectively). A negative correlation was found between air concentration and ethanol yield, while a positive correlation was confirmed between acetic acid yield and oxygenation level (Morales et al., 2015).

The impact of temperature on organic acid production by yeast

Wine fermentations are generally conducted across a wide range of temperatures, with red wine fermentation being carried out at higher temperatures $\left(18^{\circ} \mathrm{C}\right.$ to $\left.25^{\circ} \mathrm{C}\right)$ and white wine fermentation at lower temperatures $\left(10^{\circ} \mathrm{C}\right.$ to $\left.15^{\circ} \mathrm{C}\right)$. The higher fermentation temperature in red wines is essential for the extraction of anthocyanins and other non-volatile compounds from the grape skins during fermentation, while lower temperatures are recommended for the retention of fruity volatile compounds and the prevention of undesirable volatile flavour compounds in white wines (Lambrechts \& Pretorius, 2000; Styger et al., 2011; Fairbairn et al., 2014).

Torija et al. (2003) observed temperature effects on the growth of strains of $S$. cerevisiae in grape must and noted a significant increase in succinic and acetic acid as fermentation temperature increased. Aragon et al. (1998) investigated the influence of yeast type and fermentation temperature on organic acid content and observed that wines fermented at $18^{\circ} \mathrm{C}$ showed lower succinic acid content compared to those fermented at $21^{\circ} \mathrm{C}$. Significant differences were also observed for acetic acid and citric acid concentrations. Taing and Taing (2007) found that temperature (optimum at $25^{\circ} \mathrm{C}$ ) increased succinic and malic acid levels in high-sugar fermented food. Apart from wine, temperature-dependent production/consumption profiles of lactic, succinic, malic and acetic acid were previously observed in rice wine (Liu et al., 2014).

Data also suggest that the intrinsic ability of yeast strains to grow at different temperatures appears to be another influential element in terms of temperature-dependent succinic acid production during fermentation. Castellari et al. (1994) showed that mesophilic strains AWIR 796 and Endoferm $M 2$ were average producers of succinic acid, but cryo-tolerant strains of $S$. bayanus produced an additional $0.8 \mathrm{~g} / \mathrm{L}$ of succinic acid. The study concluded that succinic acid production was strain dependent. The same study also showed variations in acetic acid production among the wine yeast strains tested.

Effect of vitamins on organic acid production by yeast According to the United States Department of Agriculture (National Nutrient Database for Standard Reference
Release 28), 100 grams of grapes contain about $5.4 \mathrm{mg}$ of vitamin $\mathrm{C}, 0.09 \mathrm{mg}$ of vitamin $\mathrm{B} 1,0.2 \mathrm{mg}$ of vitamin $\mathrm{B} 2$, $0.08 \mathrm{mg}$ of vitamin B6, $0.70 \mathrm{mg}$ of vitamin $\mathrm{E}$ and $0.2 \mathrm{mg}$ of niacin. Vitamins commonly required by yeast include the following: Biotin (which serves as a cofactor in carboxylasecatalysed reactions), pantothenic acid (the functional group of coenzyme A, which is involved in acetylation reactions), nicotinic acid (in the form of nicotinamide, which is involved in redox reactions) and thiamine (in the form of thiamine pyrophosphate, which is involved in decarboxylation reactions) (Walker, 1998). Organic co-factors, such as vitamins, are required for the enzymatic complexes of several intermediates such as organic acids (Tu et al., 2005). The study of Ribéreau-Gayon et al. (1956) demonstrated that the absence of individual vitamins such as thiamine, biotin and pantothenate in synthetic medium significantly reduced succinic acid concentrations in wine, whilst increasing acetic acid and ethanol yields. In addition, a vitamin, nicotinic acid, was the limiting factor for lactic acid production during fermentation with the K1-LDH strain in batch conditions (Colombie \& Sablayrolles, 2004).

\section{Effect of nitrogen on organic acid production by yeast}

The range of yeast available nitrogen (YAN, mainly ammonium and amino acids, with the exception of proline) recommended by oenologists varies from $150 \mathrm{mg} / \mathrm{l}$ YAN (Weeks \& Henschke, 2013) to $400 \mathrm{mg}$ of nitrogen per litre (Ugliano et al., 2007). However, Zoecklein (1998) showed that maximum fermentation rates can be achieved with YAN in the 400 to $500 \mathrm{mg} \mathrm{N} / \mathrm{L}$ range, although most winemakers do not prefer higher nitrogen concentrations due to the impact that they can have on wine aroma. According to Bisson \& Butzke (2000), in order to successfully complete fermentations, optimal nitrogen levels at harvest should be part of viticulture considerations, hence sugar-nitrogen balancing is also an important aspect of fermentation. For this reason, the UC Davis Department of Viticulture and Enology made recommendations to yeast and nutrient manufacturers based on harvest Brix level (a measure of must sugar). They recommended that, at a Brix level of 21 to $27^{\circ}$ Brix, about 200 to $350 \mathrm{mg} \mathrm{N} / \mathrm{L}$ should be made available in order to successfully complete fermentation.

The nitrogen content of yeast cells is approximately $10 \%$ of cellular dry weight (Walker, 1998). Although yeast is unable to fix molecular nitrogen, simple inorganic nitrogen sources such as ammonium salts (e.g. ammonium sulphate) can be utilised effectively (Matthews \& Web, 1991; Walker \& Stewart, 2016). Yeast can also utilise nitrate and a variety of organic nitrogen compounds such as amino acids, peptides, purines, pyrimidines and amine as nitrogen sources (Webb \& Lee, 1990). Insufficient nitrogen during fermentation is one of the biggest challenges faced by yeast under fermentative conditions. Although grape must contains a broad variety of nitrogen sources, such as amino acids and ammonia, sluggish or stuck fermentations are often observed when these nitrogen sources are limited or depleted before the end of fermentation (Bisson, 1999; Sturgeon et al., 2013).

Must nitrogen content influences organic acid production in wine in many ways via mechanisms that have only been partially elucidated. According to Remize et al. 
(2000), the relationship between the initial nitrogen content (ammonium sulphate) and organic acids such as acetic acid in Saccharomyces cerevisiae during fermentation is very complex. The effect of the addition of yeast assimilable nitrogen indeed has shown an inverse relationship with acetic acid production in the initial stages of fermentation, but not in the later stages of fermentation.

The impact of different nitrogen sources on the general metabolism of $S$. cerevisiae has also been evaluated in relative depth. Camarasa et al. (2003) showed that glutamic acid has a large influence on the formation and production of $\alpha$-ketoglutaric acid, succinic acid and acetic acid. Increased concentrations of these compounds were produced during fermentation when glutamate was used as a nitrogen source as compared to ammonium and other amino acids. In a different study, increased $S$. cerevisiae growth and succinic acid production by $S$. cerevisiae were observed at increased nitrogen levels (up to $500 \mathrm{mg} / \mathrm{L}$ ). However, increases in nitrogen above the $500 \mathrm{mg} / \mathrm{L}$ level had little additional impact on the production of succinic acid and acetic acid (Heerde \& Radler, 1978). Vilanova et al. (2007) also revealed that ammonium supplementation increases the final concentration of L-malic acid, acetic acid and glycerol in wine. Furthermore, higher amounts of proline in cultivars such as Chardonnay, Riesling and Sauvignon blanc were reportedly responsible for higher succinic acid production in the wine (Batch et al., 2009).

The availability of nitrogen sources is central to the utilisation of aspartate and glutamate via the reductive and oxidative arms of the TCA cycle respectively (Camarasa et al., 2003). Several authors have reported an increase in succinic acid production when growth media contained glutamate and aspartate as the major nitrogen sources for yeast (Roustan \& Sablayrolles, 2002). Agarwal et al. (2007) also investigated the effect of nitrogen sources (among others peptone, urea, tryptone and ammonium sulphate) on enzymes involved in succinic acid production. Supplying tryptone as a nitrogen source resulted in the elevated formation of succinic acid $(3.8 \mathrm{~g} / \mathrm{L})$, as the activities of enzymes involved in succinic acid production were found to have increased. Among the inorganic nitrogen sources tested, ammonium hydrogen phosphate yielded a maximum of $2.43 \mathrm{~g} / \mathrm{L}$ of succinic acid.

\section{Effect of sugar on organic acid production by yeast}

Under normal circumstances, viticulturists prefer to pick the grapes when the sugars are in specific ranges, depending on the varietal and the style of wine that is targeted. Most wines are harvested at sugar levels of between 190 and $250 \mathrm{~g} / \mathrm{L}$, with the sugar composed of similar amounts of glucose and fructose (Boulton et al., 1995). Saccharomyces usually converts $95 \%$ of the sugar to ethanol and carbon dioxide, while $1 \%$ is converted to cellular material and the remaining $4 \%$ is converted to other end products such as organic acids, higher alcohols and esters and, to a lesser extent, aldehydes (Rapp, 1998). However, there are other end products, such as acetaldehyde, acetic acid, ethyl acetate, higher alcohols and diacetyl, which may be regarded as undesirable when present in excess concentrations.

Factors that affect the production of some organic acids, and in particular of acetic acid, have been studied extensively
(Usseglio-Tomasset, 1995; Bisson, 1999; Bely et al., 2005; Ferreira et al., 2006). In very high-sugar Riesling ice wine juices (over $400 \mathrm{~g} / \mathrm{L}$ ), alcoholic fermentation tends to result in very low ethanol yields and high acetate production (Caridi, 2003). Pigeau et al. (2007) also noted that increasing ice wine juice sugar concentration from 40 to $46^{\circ}$ Brix decreased yeast growth, sugar consumption rate, the total amount of sugar consumed and the total amount of ethanol produced. However, acetic acid levels increased from $0.11 \mathrm{~g} / \mathrm{L}$ (at $40^{\circ}$ Brix) to $0.21 \mathrm{~g} / \mathrm{L}$ (at $46^{\circ} \mathrm{Brix}$ ). A reasonable hypothesis for these findings could be the increased osmotic stress imposed by higher initial sugar contents, leading to higher initial glycerol formation and thus indirectly to acetic acid formation due to redox balancing (Erasmus et al., 2004). Based on these observations, the influence of sugar levels on organic acid production appears to be significant, although no conclusive trends have been established.

Effect of yeast strain on organic acid production in wine Numerous studies have provided insights into the response of individual strains to the grape must of specific cultivars and their impact on the sensory and chemical characteristics of the wines produced.

In the case of $S$. cerevisiae, many papers have reported on the influence of yeast strain on wine composition in general (Delfini et al., 1994, Galletti et al., 1996; KunickaStyczyńska \& Pogorzelski, 2009, Chidi et al., 2015). Aragon et al. (1998) specifically addressed the influence of yeast strain on the organic acid composition of wine. The results showed significant differences in acetic, citric and succinic acid production for different yeast strains. Patel \& Shibamoto (2003) investigated a total of 18 S. cerevisiae yeast strains for the production of volatile acidity, primarily acetic acid. Of all the strains, the composition of the volatile acidity produced by the $A 350 / V L 1 / F$ ermiblanc and $T 73$ yeast strains were significantly different from the other strains and contributed significantly to the final characteristic flavours in the corresponding wines. Previously, Kunicka-Styczyńska \& Pogorzelski. (2009) also observed significant variations in pyruvic and acetic acid levels when different Saccharomyces species were assessed in apple wines. Although there are many other factors that directly/indirectly affect acid degradation/evolution in wine, strain identity seems to be one of the major drivers. Recently, wine strain identity was also regarded as the main factor controlling the organic acid profiles of red and white wine in South Africa (Chidi et al., 2015).

A diversity of yeast species within the genera Hanseniaspora, Pichia, Kluyveromyces, Candida and Saccharomyces have long been known to be present in freshly crushed grape juice and in the early stages of fermentation (Bisson, 1993). However, there is very little information on how these yeast species affect organic acid production in wine.

\section{Impact of osmotic stress on major fermentation products of yeast}

The ability of wine yeast to carry out alcoholic fermentation under winemaking conditions is largely influenced by its response to the stress conditions such as osmotic stress 
(Carrasco-Portugal et al., 2001). Different mechanisms have been developed by the fermenting strains to triumph over these adverse situations. A clear understanding of these mechanisms is essential to improve the overall fermentation process and thus improve the quality of wines (Ivorra et al., 2000).

During osmotic stress, glycerol is produced in response to high sugar levels in the must, resulting in excess $\mathrm{NAD}^{+}$. To counterbalance the high levels of $\mathrm{NAD}^{+}$production, $\mathrm{NADH}$ is regenerated by converting acetaldehyde to acetic acid (Caridi et al., 2003). Glycerol metabolism thus plays an essential role in fermentation, not only as an osmo-protectant, but also by aiding the equilibration of the intracellular redox balance (Romano \& Suzzi, 1993; Jain, 2010). Beney \& Gervais (2001) also found that the resistance of $S$. cerevisiae to high osmotic stress improved at lower temperatures compared to warmer conditions, but a link to organic acid levels was not established. Galafassi et al. (2013) showed that osmotic stress is responsible for the production and accumulation of intracellular glycerol in the wine yeast Dekkera bruxellensis. Higher expression of NADH-dependent glycerol-3phosphate dehydrogenase (GPD) activity was observed as a result. The effect of hyperosmotic stress on acetic acid levels was recently demonstrated in ice wines (high-sugar must) (Yang et al., 2017). The authors showed a direct relationship between hyperosmotic stress and the catalysis of $\mathrm{NAD}^{+}$dependent aldehyde dehydrogenase(s) (Aldp(s)), which eventually leads to higher acetic acid production in wines.

Although the current review focuses much attention on several factors that do or may affect organic acid degradation or evolution in wine, very little literature is available on how multiple changes in two or more parameters may affect wine acidity. This is not surprising, since multifactorial experiments are not easy to interpret. Notwithstanding these obstacles, more work is required to investigate the influences of individual and/or multiple changes in wine yeast strains, fermentation $\mathrm{pH}$, sugar and temperature on the acid profiles of different wines.

\section{The importance of "omics" tools in wine research Transcriptomic and proteomic approaches in yeast research} Transcriptome and proteome profiles for several wine yeast strains have been established previously under winemaking conditions (Rossouw et al., 2008, Gomez-Pastor et al., 2010), and many studies have paid special attention to the intrinsic genetic and regulatory pathways that are actively involved in wine fermentation (Erasmus et al., 2003; Rossignol et al., 2003; Varela et al., 2005; Mendes-Ferreira et al., 2007; Marks et al., 2008; Pizarro et al., 2008; Barbosa et al., 2015). A global analysis of gene expression and protein profiles plays an important role in increasing our understanding of how yeast cells adapt to environmental changes, and how their response to environmental conditions affects cellular metabolism and the production of primary and secondary compounds important to wine quality.

Wine fermentation is a process during which yeast must adapt to the significant changes that occur during vinification (Zuzuarregui et al., 2006). At the end of the biological information-transfer system (from genome, to transcriptome, to proteome), the post-translational modifications at the protein level and/or protein activity play an essential role in further adjustments of the cell to these changing external conditions. Efforts have been made in recent years to investigate gene expression profiles during vinification. The detailed analysis of subsets of genes, transcriptional regulation and gene expression profiles in yeast under winemaking conditions has been the focus of several studies (Puig \& Perez, 2000; Rossignol et al., 2006; Rossouw et al., 2008; Margalef-Català et al., 2016).

Previously, commercial wine strains were screened and selected on the basis of desired physiological traits for optimised fermentation performance, but this was not accompanied by knowledge with regard to the molecular basis for the fermentation phenotypes of these selected strains (Aranda \& Del Olmo, 2004). The study of Zuzuarregui et al. (2006) offered the first proteomic and transcriptomic comparisons involving two commercial strains (ICV 16 and $I C V$ 27) with different fermentative performances. Since then, several other combinatorial transcriptomic-proteomic studies of wine yeast have been carried out (Rossignol et al., 2003; Gomez-Pastor et al., 2010; Orellana et al., 2014). The use of these global analysis strategies has made it possible to analyse variations in gene expression and protein levels at different time points during vinification, and have greatly enhanced our understanding of yeast metabolism during fermentation (Marks et al., 2003). However, and to our knowledge, such approaches have not yet been applied with regard to the genetic regulation of organic acid production. The potential thus exists to utilise these tools with a specific focus on organic acid metabolism in different yeast strains to gain new insights into the regulation of acid metabolism on a molecular level.

\section{Metabolomics of yeast}

The major goal of systems biology is to acquire an overall quantitative description of systems that occur inside the cell. It is a challenging task, as the components and interactions involved in these cellular systems are both numerous and complex (Cakir et al., 2006). Although transcriptome data supplies an overview of the broad expression patterns and regulation of genes involved in metabolism, understanding functional cellular physiology requires metabolomic data to complete the systems picture (Nielsen, 2003).

The metabolomics of wine have been studied extensively over the past few years (Son et al., 2009; Van Dorsten et al., 2009; Cuadros et al., 2010; Orellana et al., 2014). Cuadros et al. (2010) provided data demonstrating that unbiased and objective analytical chemistry, in combination with multivariate statistical methods, allows reproducible classification of wine attributes such as variety, origin, vintage and quality through metabolomics studies. Son et al. (2009) investigated the changes in metabolites such as pyruvate, succinate, citrate, malate and tartrate in musts during alcoholic fermentation and during ageing by coupling ${ }^{1} \mathrm{H}$ NMR spectroscopy with multivariate statistical analysis. Elsewhere, the contribution of individual volatile aroma compounds to the overall volatile composition was also accomplished through the development of automated metabolomics data analysis of GC-MS profiles of wines (Schmidtke et al., 2013). In addition, the analysis of wine 
micro-oxygenation has also been attempted by untargeted LC-MS (Arapitsas et al., 2012). Recently, Geana et al. (2016) successfully classified red wines using suitable markers coupled with multivariate statistical analysis.

The functional analysis of cellular metabolism and integration of metabolome data with other omics data (e.g. transcriptome data) necessitates the large-scale detection and quantification of metabolites of interest. However, a noteworthy challenge is the shortage of targeted quantitative analyses for metabolomics approaches (Nielsen, 2003). Devantier et al. (2005) generated a high-throughput GCMS method for quantifying metabolites that permits semiquantitative analysis of several metabolites in Saccharomyces cerevisiae. Similar metabolomics techniques could also act as valuable tools that will expand our knowledge regarding organic acid metabolism of yeast in wine.

\section{CONCLUSIONS}

Wine acidity contributes significantly to the consumer perception of wine quality. Winemakers have always been challenged in terms of acid management and the balance between sugar and acidity in their wines (both in warmand cool-climate viticultural regions). While researchers are currently investigating acid evolution in wine, the key issue that is often overlooked by winemakers is how individual organic acids contribute to the flavour profile and organoleptic characteristics of wines. In recent years, the development of several analytical techniques (i.e. electrophoretic, chromatographic and enzymatic) for metabolite quantification has received considerable attention in wine science. Rapid, sensitive and accurate analytical techniques for the quantification of organic acids that are present in wine provide the platform for detailed analysis of these organic acids across a range of experimental conditions. Intelligent experimental design, combined with suitable analytical techniques, form the foundation of meaningful studies of yeast acid metabolism. This will ultimately provide winemakers with a better understanding of acid development in their wines, and of adjustment or management practices in the cellar to favour desirable acid profiles. Factors that impact significantly on the production of organic acids in wine must be investigated thoroughly (with the help of complementary systems biology approaches) in order understand the fundamental metabolic regulation underlying the evolution of acidity during fermentation.

\section{LITERATURE CITED}

Aceituno, F.F., Orellana, M., Torres, J., Mendoza, S., Slater, A.W., Melo, F. \& Agosin, E., 2012. Oxygen response of the wine yeast Saccharomyces cerevisiae EC1118 grown under carbon-sufficient, nitrogen-limited ecological conditions. Appl. Environ. Microbiol. 78, 8340-8352.

Agarwal, L., Isar, J., Meghwanshi, G.K. \& Saxena, R.K., 2007. Influence of environmental and nutritional factors on succinic acid production and enzymes of reverse tricarboxylic acid cycle from Enterococcus flavescens. Enz. Micr. Tech. 40(4), 629-636.

Akin, H., Brandam, C., Meyer, X. \& Strehaiano, P., 2008. A model for $\mathrm{pH}$ determination during alcoholic fermentation of a grape must by Saccharomyces cerevisiae. Chem. Eng. Prog. 47, 1986-1993.
Albers, E., Larsson, C., Lidén, G., Niklasson, C. \& Gustafsson, L., 1996. Influence of the nitrogen source on anaerobic growth and product formation. Appl. Environ. Microbiol. 62, 3187-3195.

Alberts, B., Bray, D., Lewis, J., Raff, M., Roberts, K. \& Watson, J.D., 1994 $\left(3^{\text {rd }}\right.$ ed). The molecular biology of the cell. Garland Publishing Co., New York

Apichai, S., Pattana, T., Rodjana, B. \& Supalax S., 2007. Capillary zone electrophoresis of organic acids in beverages. LWT Food Sci. Technol. 40, 1741-1746.

Aragon, P., Atienza, J. \& Climent, M.D., 1998. Influence of clarification, yeast type and fermentation temperature on the organic acid and higher alcohols of Malvasia and Muscatel Wines. Am. J. Enol. Vitic. 49(2), 211219.

Aranda, A. \& Del Olmo, M., 2004. Exposure of Saccharomyces cerevisiae to acetaldehyde induces sulfur amino acid metabolism and polyamine transporter genes, which depend on Met $4 \mathrm{p}$ and Haalp transcription factors, respectively. Appl. Environ. Microbiol. 70, 1913-1922.

Arapitsas, P., Scholtz, M., Vrhovsek, U., Di Blasi, S., Bartolini, A.B., Masuero, D., Perenzoni, D., Rigo, A. \& Mattivi, F., 2012. A metabolomic approach to the study of wine micro-oxygenation. PLOS ONE 7(5), e37783. doi:10.1371/journal.pone. 0037783

Barbosa, C., García-Martínez, J., Pérez-Ortín, J.E. \& Mendes-Ferreira, A., 2015. Comparative transcriptomic analysis reveals similarities and dissimilarities in Saccharomyces cerevisiae wine strains response to nitrogen availability. PLOS ONE 10(4), p.e0122709.

Bartowsky, E.J. \& Henschke, P.A., 2004. The 'buttery' attribute of winediacetyl desirability, spoilage and beyond. Int. J. Food Microbiol. 96, 235252

Bartowsky, E.J., Xia, D., Gibson, R.L., Fleet, G.H. \& Henschke, P.A., 2003. Spoilage of bottled red wine by acetic acid bacteria. Lett. Appl. Microbial. $36,307-314$.

Batch, B., Sauvage, F.X., Dequin, S. \& Camarasa, C., 2009: Role of $\gamma$-aminobutyric acid as a source of nitrogen and succinate in wine. Am. J. Enol. Vitic. 60, 508-516.

Bauer, R. \& Dicks, L.M.T., 2005. Control of malolactic fermentation in wine. A review. Int. J. Food Microbiol. 25, 201-216.

Bely, M., Rinaldi, A. \& Dubourdieu, D., 2003. Influence of assimilable nitrogen on volatile acidity production by Saccharomyces cerevisiae during high sugar fermentation. J. Biosci. Bioeng. 96, 507-512.

Beney, L. \& Gervais, P., 2001. Influence of the fluidity of the membrane on the response of microorganisms to environmental stresses. Appl. Microbiol. Biotechnol. 57(1-2), 34-42.

Benito, M.J., Ortiz, M.C., Sanchez, A.S., Sarabia, L.A. \& Iniquez, M., 1999. Typification of vinegars from Jerez and Rioja using classical chemometric techniques and neural network methods. Analyst 124(4), 547-552.

Bertolini, L., Zambonelli, C., Giudici, P. \& Castellari, L., 1996. Higher alcohol production by cryotolerant Saccharomyces strains. Am. J. Enol Vitic. 47, 343-345.

Betteridge, A., Grbin, P. \& Jiranek, V., 2015. Improving Oenococcus oeni to overcome challenges of wine malolactic fermentation. Trends Biotechnol. $33(9), 547-553$

Bisson, L.F., 1993. Yeast - Metabolism of sugars. In Fleet, G.H. (ed). Wine microbiology and biotechnology. Chur, Switzerland, Harwood Academic Publishers. pp. $55-75$.

Bisson, L.F., 1999. Stuck and sluggish fermentations. Am. J. Enol. Vitic. 50, 107-119.

Bisson, LF. \& Butzke, C.E., 2000. Diagnosis and rectification of stuck and sluggish fermentations. Am. J. Enol. Vitic. 51, 168-177. 
Bisson, L.F. \& Walker, G.A., 2015. The microbial dynamics of wine fermentation. In: Holzapfel, W. (ed.). Advances in fermented foods and beverages. Elsevier, Amsterdam. pp. 435 - 476.

Boulton, R.B., Singleton, V.L., Bisson, L.F. \& Kunkee, R.E., 1996. Principles and practices of winemaking. Chapman and Hall, New York.

Cakir, T., Patil, K.R., Onsan, Z.I., Ülgen, K.O., Kirdar, B. \& Nielsen, J., 2006. Integration of metabolome data with metabolic networks reveals reporter reactions. Mol. Syst. Biol. 2, 50-61.

Camarasa, C., Grivet, J.P. \& Dequin, S., 2003. Investigation by 13C-NMR and tricarboxylic acid (TCA) deletion mutant analysis of pathways for succinate formation in Saccharomyces cerevisiae during anaerobic fermentation. Microbiol. 149, 2669-2678.

Caridi, A., 2003. Effect of protectants on wine yeasts under osmotic stress. Food. Technol. Biotechnol. 41(2), 145-148.

Carrasco-Portugal, M.C., Granados-Soto, V., Reyes-Garcia, G., MedinaSantillán, R., Herrera, J.E. \& Flores-Murrieta, F.J., 2001. Multiple-dose pharmacokinetics of fluoxetine in healthy Mexican subjects. Proc. West Pharmacol. Soc. 44, 69-70.

Cartledge, T.G., 1987. Substrate utilization, non-carbohydrate substrates. In: Berry, D.R., Russel, I. \& Stewart, G.G. (eds). Yeast biotechnology. Allen and Unwin, London. pp. $311-342$.

Castellari, L., Ferruzzi, M., Magrini, A., Giudici, P., Passarelli, P. \& Zambonelli, C., 1994. Unbalanced wine fermentation by cryotolerant vs. non-cryotolerant Saccharomyces strains. Vitis 33, 49-52.

Castellari, M., Versari, A., Spinabelli, S., Galassi, S. \& Amati, A., 2000. An improved HPLC method for the analysis of organic acids, carbohydrates and alcohols in grape must and wines. J. Liq. Chrom. Rel. Technol. 23, 2047-2056.

Cheynier, V., Masson, G., Rigaud, J. \& Moutounet, M., 1993. Estimation of must oxidation during pressing in Champagne. Am. J. Enol. Vitic. 44, 393-399.

Chidi, B.S., Rossouw, D., Buica, A.S. \& Bauer, F.F., 2015. Determining the impact of industrial wine yeast strains on organic acid production under white and red wine-like fermentation conditions. S. Afr. J. Enol. Vitic. 36(3), 316-327.

Colombie, S. \& Sablayrolles, J.M., 2004. Nicotinic acid controls lactate production by K1-LDH: A Saccharomyces cerevisiae strain expressing a bacterial $L D H$ gene. J. Ind. Microbiol. Biotechnol. 31, 209-215.

Conde, B.C, Silva, P., Fontes, N., Dias, A.C.P., Tavares, R.M., Sousa, M.J., Agasse, A., Delrot, S. \& Geros, H., 2007. Biochemical changes throughout grape berry development and fruit and wine quality. Food 1, 1-22

Conrad, M., Schothorst, J., Kankipati, H.N., Van Zeebroeck, G., RubioTexeira, M. \& Thevelein, J.M., 2014. Nutrient sensing and signaling in the yeast Saccharomyces cerevisiae. FEMS Microbiol. Rev. 38(2), 254-299.

Cortacero-Ramírez, S., Segura-Carretero, A., de Castro, M.H.B. \& Fernández-Gutierrez, A., 2005. Determination of low-molecular-mass organic acids in any type of beer samples by co-electroosmotic capillary electrophoresis. J. Chrom. A. 1064, 115-119.

Cuadros-Inostroza, A., Giavalisco, P., Hummel, J., Eckardt, A., Willmitzer, L. \& Pena-Cortes, H., 2010. Discrimination of wine attributes by metabolome analysis. Anal. Chem. 82, 3573-3580.

Darias-Martín, J.J., Rodríguez, O., Díaz, E. \& Lamuela-Raventós, R.M., 2000. Effect of skin contact on the antioxidant phenolics in white wine. Food Chem. 71, 483-487.

De Barros Lopes, M., Rehman, A.U., Gockowiak, H., Heinrich, A.J., Langridge, P. \& Henschke, P.A., 2000. Fermentation properties of a wine yeast overexpressing the Saccharomyces cerevisiae glycerol 3-phosphate dehydrogenase gene (GPD2). Aust. J. Grape Wine Res. 6, 208-215.
Defilippi, B.G., Manríquez, D., Luengwilai, K. \& GonzálezAgüero, M., 2009. Aroma volatiles: Biosynthesis and mechanisms of modulation during fruit ripening. Adv. Bot. Res. 50, 1-37.

Delfini, C., Cocito, C. \& Conterno, L., 1994. Scientific findings on the interaction between must composition and aromatic response of yeast. Enotecnico 30(7/8), 65-74.

Devantier, R., Scheithauer, B., Villas-Bôas, S.G., Pedersen, S. \& Olsson, L., 2005. Metabolite profiling for analysis of yeast stress response during very high gravity ethanol fermentations. Biotechnol. Bioeng. 90, 703-714.

Donnelly, M., Millard, C.S., Clark, D.P., Chen, M. \& Rathke, J., 1998. A novel fermentation pathway in an Escherichia coli mutant producing succinic acid, acetic acid and ethanol. Appl. Biochem. Biotechnol. 70-72, 187-198.

Du Toit, W.J., Marais, J., Pretorius, I.S. \& Du Toit, M., 2006. Oxygen in wine: A review. S. Afr. J. Enol. Vitic. 27, 76-94.

Eglinton, J.M., Heinrich, J.A., Langridge, P., Henschke, P.A. \& De Barros Lopes, M., 2002. Decreasing acetic acid accumulation by a glycerol overproducing strain of Saccharomyces cerevisiae by deleting the ALD6 aldehyde dehydrogenase gene. Yeast 19(4), 295-301.

Erasmus, D.J., Cliff, M. \& Van Vuuren H.J.J., 2004. Impact of yeast strain on the production of acetic acid, glycerol, and the sensory attributes of icewine. Am. J. Enol. Vitic. 55, 371-378.

Erasmus, D.J., Van der Merwe, G.K. \& Van Vuuren, H.J.J., 2003. Genomewide expression analyses: Metabolic adaptation of Saccharomyces cerevisiae to high sugar stress. FEMS Yeast. Res. 3, 375-399.

Estela-Escalante, W., Rychtera, M., Melzoch, K. \& Hatta-Sakoda, B., 2012. Effect of aeration on the fermentative activity of Saccharomyces cerevisiae cultured in apple juice. Rev. Mex. Ing. Quím 11(2), 211-226.

Estruch, F., 2000. Stress-controlled transcription factors, stress-induced genes and stress tolerance in budding yeast. FEMS Microbiol. Rev. 24, 469486.

Fairbairn, S.C., Smit, A.Y., Jacobson, D., Prior, B.A. \& Bauer, F.F., 2014. Environmental stress and aroma production during wine fermentation. S. Afr. J. Enol. Vitic. 35(2), 168-177.

Fernie, A.R., Carrari, F. \& Sweetlove, L.J., 2004. Respiratory metabolism: Glycolysis, the TCA cycle and mitochondrial electron transport. Curr. Opin. Plant. Biol. 7(3), 254-261.

Ferreira, J., Du Toit, M. \& Du Toit, W.J., 2006. The effects of copper and high sugar concentrations on growth, fermentation efficiency and volatile acidity production of different commercial wine yeast strains. Aust. J. Grape Wine Res. 12, 50-56.

Finley, K.R., Huryta, J.M., Mastel, B.M., Mcmullin, T.W., Poynter, G.M., Rush, B.J., Watts, K.T., Fosmer, A.M., Mcintosh, J.R.V.L. \& Brady, K.M., 2012. Compositions and methods for succinate production. Patent WO2012103261 A2.

Flores, C.L., Rodriguez, C., Petit, T. \& Gancedo, C., 2000. Carbohydrate and energy-yielding metabolism in non-conventional yeasts. FEMS Microbiol. Rev. 24, 507-529.

Fowles, G.W.A., 1992. Acids in grapes and wines: A review. J. Wine Res. 3(1), 25-41.

Fugelsang, K.C. \& Edwards, C.G., 2007. Wine microbiology: Practical applications and procedures. Springer Verlag, New York.

Galafassi, S., Toscano, M., Vigentini, I., Piškur, J. \& Compagno, C., 2013. Osmotic stress response in the wine yeast Dekkera bruxellensis. Food Microbiol. 36(2), 316-319.

Gallander, J.F., 1977. Deacidification of Eastern table wines with Schizosaccharomyces pombe. Am. J. Enol. Vitic. 28, 65-68. 
Galletti, G.C., Camacini, A., Antonelli, A. \& Farris, G.A., 1996. Volatile composition of Vernaccia di Oristano sherry-like wine as affected by biological ageing. J. Sci. Food Agric. 70(1), 44-50.

Geana, E.I., Popescu, R., Costinel, D., Dinca, O.R., Ionete, R.E., Stefanescu, I., Artem, V. \& Bala, C., 2016. Classification of red wines using suitable markers coupled with multivariate statistical analysis. Food Chem. 192, 1015-1024.

Ghosh, S., Chakraborty, R., Chatterjee, G. \& Raychaudhuri, U., 2012 Study on fermentation conditions of palm juice vinegar by response surface methodology and development of a kinetic model. Braz. J. Chem. Eng. 29(3), 461-472.

Gomez-Pastor, R., Perez-Torrado, R., Cabiscol, E. \& Matallana, E., 2010. Transcriptomic and proteomic insights of the wine yeast biomass propagation process. FEMS Yeast. Res. 10, 870-884.

Goold, H.D., Kroukamp, H., Williams, T.C., Paulsen, I.T., Varela, C. \& Pretorius, I.S., 2017. Yeast's balancing act between ethanol and glycerol production in low-alcohol wines. Microb. Biotechnol. 10(2), 264-278.

Graham, R.A., 1979. Influence of yeast strain and $\mathrm{pH}$ on pyruvic acid production during alcoholic fermentation. Am. J. Enol. Vitic. 30, 4318-320.

Heerde, E. \& Radler, F., 1978. Metabolism of the anaerobic formation of succinic acid by Saccharomyces cerevisiae. Arch. Microbiol. 117, 269-276.

Hohmann S., 2002. Osmotic adaptation in yeast - Control of the yeast osmolyte system. Int. Rev. Cytol. 215, 149-187.

Ivorra, C., Díez, A., Cortés, M.J., Poch, E., Sanz-González, S.M. \& Andrésm, V., 2000. Inhibition of cellular proliferation by drug targeting of cyclin-dependent kinases. Curr. Pharm. Biotechnol. 1(1), 107-116.

Jackson, D. \& Schuster, D., 1997. The production of grapes \& wine in cool climates. Lincoln University Press, Canterbury, New Zealand.

Jackson, R. S., 2008. Biochemistry of alcoholic fermentation. In: Wine Science, Principles and Applications, San Diego, USA. pp. 358-363.

Jain, V.K., 2010. Modifying redox potential and its impact on metabolic fluxes in Saccharomyces cerevisiae. Dissertation, Stellenbosch University, Private Bag XI, 7602 Matieland (Stellenbosch), South Africa.

Jost, P. \& Piendl, A., 1975. Technological influences on the formation of acetate during fermentation. Am. Soc. Brew. Chem. 34, 31-37.

Kalathenos, P., Sutherland, J.P. \& Roberts, T.A., 1995. Resistance of some wine spoilage yeasts to combinations of ethanol and acids present in wine. J. Appl. Bacteriol. 78, 245.

Kandl, T. \& Kupina, S., 1999. An improved capillary electrophoresis procedure for the determination of organic acids in grape juice and wine Am. J. Enol. Vitic. 50, 155-161.

Khan, Z. \& Dwivedi, A.K., 2013. Fermentation of biomass for production of ethanol: A review. Univers. J. Environ. Res. Technol. 3(1), 1-13.

Krueger, D.A., 2012. Composition of pomegranate juice. J. AOAC Int. 95, 63-68.

Kučerová, J. \& Široký, J., 2014. Study of changes organic acids in red wines during malolactic fermentation. Acta Univ. Agric. Silvic. Mendel. Brun. 59(5), 145-150

Kunicka-Styczyńska, A. \& Pogorzelski, E., 2009. L-malic acid effect on organic acid profiles and fermentation by-products in apple wines. Czech. J. Food Sci. 27, 228-231.

Kupina, S.A., Pohl, C.A. \& Gannotti J.L., 1991. Determination of tartaric, malic, and citric acids in grape juice and wine using gradient ion chromatography. Am. J. Enol. Vitic. 42, 1-5
Kuyper, M., Winkler, A., Van Dijken, J.P. \& Pronk, JT., 2004. Minimal metabolic engineering for efficient anaerobic xylose fermentation: A proof of principle. FEMS Yeast. Res. 4(6), 655-664.

Lambrechts, M.G. \& Pretorius, I.S., 2000 .Yeast and its importance in wine aroma - A review. S. Afr. J. Enol. Vitic. 21, 97-129.

Lamikanra, O., 1997. Changes in organic acid composition during fermentation and aging of noble muscadine wine. J. Agric. Food. Chem. $45(3), 935-937$

Lee, Y.J., Jang, J.W., Kim, K.J. \& Maeng, P.J., 2011. TCA cycle-independent acetate metabolism via the glyoxylate cycle in Saccharomyces cerevisiae. Yeast 28, 153-166.

Lerena, M.C., Rojo, M.C., Sari, S., Mercado, L.A., Krieger-Weber, S. \& Combina, M., 2016. Malolactic fermentation induced by Lactobacillus plantarum in Malbec wines from Argentina. S. Afr. J. Enol. Vitic. 37(2), 115-123.

Liu, D., Zhang, H., Xu, B. \& Tan, J., 2014. Influence of fermentation temperature and source of enzymes on enological characteristics of rice wine. J. Inst. Brew. 120(3), 231-237.

Liu, X., Jia, B., Sun, X., Ai, J., Wang, L., Wang, C., Zhao, F., Zhan, J. \& Huang, W., 2015. Effect of initial $\mathrm{pH}$ on growth characteristics and fermentation properties of Saccharomyces cerevisiae. J. Food Sci. 80, 800808 .

Lonvaud-Funel, A., 1999. Lactic acid bacteria in the quality improvement and depreciation of wine. Antonie Leeuwenhoek 76, 317-331.

López, I., López, R., Santamaría, P., Torres, C. \& Ruiz-Larrea, F., 2008. Performance of malolactic fermentation by inoculation of selected Lactobacillus plantarum and Oenococcus oeni strains isolated from Rioja red wines. Vitis 47(2), 123-129.

Lucio, O., Pardo, I., Heras, J.M., Krieger-Weber, S. \& Ferrer, S., 2017. Use of starter cultures of Lactobacillus to induce malolactic fermentation in wine. Aust. J. Grape Wine Res. 23(1), 15-21.

Maicas, S., 2001. The use of alternative technologies to develop malolactic fermentation in wine. AAppl. Microbiol. Biotechnol. 56(1), 35-39.

Margalef-Català, M., Araque, I., Bordons, A., Reguant, C. \& BautistaGallego, J., 2016. Transcriptomic and proteomic analysis of Oenococcus oeni adaptation to wine stress conditions. Front. Microbiol. 7, 1554 doi:10.3389/fmicb.2016.01554

Margalit, Y., 1997. Concepts in wine chemistry. Wine Appreciation Guild Ltd., San Francisco.

Marks, V.D., Ho-Sui, S.J., Erasmus, D., Van der Merwe, G.K., Brumm, J., Wasserman, W.W., Bryan, J. \& Van Vuuren, H.J.J., 2008. Dynamics of the yeast transcriptome during wine fermentation reveals a novel fermentation stress response. FEMS Yeast. Res. 8, 35-52.

Marks, V.D., Van der Merwe, G.K. \& Van Vuuren, H.J.J., 2003. Transcriptional profiling of wine yeast in fermenting grape juice: regulatory effect of diammonium phosphate. FEMS Yeast. Res. 3, 269-287.

Mato, I., Huidobro, J.F., Simal-Lozano, J. \& Sancho, M.T., 2006. Simultaneous determination of organic acids in beverages by capillary zone electrophoresis. Anal. Chim. Acta 565, 190-197.

Mato, I., Suárez-Luque, S. \& Huidobro, J.F., 2005. A review of the analytical methods to determine organic acids in grape juices and wines. Food. Res. Int. $38,1175-1188$.

Matthews, T.M. \& Webb, C., 1991. Culture systems. In: Tuite, M.F. \& Oliver, S.G, (eds). Saccharomyces. Plenum Press, New York. pp. 249 - 282.

Mendes-Ferreira, A., Del Olmo, M., García-Martínez, J., Jiménez-Martí, E., Mendes-Faia A., Pérez-Ortín, J.E. \& Leão, C., 2007. Transcriptional response of Saccharomyces cerevisiae to different nitrogen concentrations during alcoholic fermentation. Appl. Environ. Microbiol. 73, 3049-3060. 
Michnick, S., Roustan, L.J., Remize. F., Barre. P. \& Dequin. S., 1997. Modulation of glycerol and ethanol yields during alcoholic fermentation in Saccharomyces cerevisiae strains overexpressed or disrupted for GPD1 encoding glycerol 3-phosphate dehydrogenase. Yeast 13, 783-793.

Moller, K., Olsson, L. \& Piskur, J., 2001. Ability for anaerobic growth is not sufficient for development of the petite phenotype in Saccharomyces kluyveri. J. Bacteriol. 183, 2485-2489.

Morales, P., Rojas, V., Quiros, M. \& Gonzalez, R., 2015. The impact of oxygen on the final alcohol content of wine fermented by a mixed starter culture. Appl. Microbiol. Biotechnol. 99, 3993-4003.

Navarrete, C., Nielsen, J. \& Siewers, V., 2014. Enhanced ethanol production and reduced glycerol formation in fps $1 \Delta$ mutants of Saccharomyces cerevisiae engineered for improved redox balancing. AMB Express 4(1), 86.

Nielsen, J., 2003. It is all about metabolic fluxes. J. Bacteriol. 185, 70317035 .

Nielsen, M.K. \& Arneborg, N., 2007. The effect of citric acid and pH on growth and metabolism of anaerobic Saccharomyces cerevisiae and Zygosaccharomyces bailii cultures. Food. Microbiol. 24(1), 101-105.

OIV (Office Internationale de la Vigne et du Vin), 2010. International code of oenological practices. OIV, Paris.

Orellana, M., Aceituno, F.F., Slater, A.W., Almonacid, L.I., Melo, F. \& Agosin, E., 2014. Metabolic and transcriptomic response of the wine yeast Saccharomyces cerevisiae strain EC1118 after an oxygen impulse under carbon-sufficient, nitrogen-limited fermentative conditions. FEMS Yeast Res. 14(3), 412-424

Osborne, J.P., Mira de Orduña, R., Liu, S.-Q. \& Pilone, G.J., 2000. Acetaldehyde metabolism by wine lactic acid bacteria. FEMS Microbiol. Lett. 191, 51-55.

Park, J.M., Shin, J.A., Lee, J.H. \& Lee, K.T., 2017. Development of a quantitative method for organic acid in wine and beer using high performance liquid chromatography. J. Food Sci. Technol. 26(2), 349-355.

Patel, S. \& Shibamoto, T., 2003. Effect of 20 different yeast strains on the production of volatile components in Symphony wine. J. Food Comps. Anal. 16(4), 469-476.

Pereira, V., Camara, J.S., Cacho, J. \& Marques, J.C., 2010. HPLC-DAD methodology for the quantification of organic acids, furans and polyphenols by direct injection of wine samples. J. Sep. Sci. 33, 1204-1215.

Petrie, P.R. \& Sadras, V.O., 2007. Advancement of grapevine maturity in Australia between 1993 and 2006: Putative causes, magnitude of trends and viticultural consequences. Eur. Journal Agro. (in press).

Pezley, M.E., 2015. Production of free sulfur dioxide by wine yeasts. J. Int. Undergrad. Res. 1(1), 27-32.

Pigeau, G.M., Bozza, E., Kaiser, K. \& Inglis, D.L., 2007. Concentration effect of Riesling Icewine juice on yeast performance and wine acidity. J. Appl. Microbiol. 103, 1691-1698.

Pinu, F.R. \&Villas-Boas, S.G., 2017. Rapid quantification of major volatile metabolites in fermented food and beverages using gas chromatographymass spectrometry. Metabolites 7(3), 37.

Pizarro, F.J., Jewett, M.C., Nielsen, J. \& Agosin, E., 2008. Growth temperature exerts differential physiological and transcriptional responses in laboratory and wine strains of Saccharomyces cerevisiae. Appl. Environ. Microbiol. 74, 6355-6368.

Popov, V.N., Moskalev, E.A., Shevchenko, M.U. \& Eprintsev, A.T., 2005. Comparative analysis of glyoxylate cycle key enzyme isocitrate lyase from organisms of different systematic groups. J. Evol. Biochem. Physiol. 41(6), 631-639.
Prior, B., Toh, T., Jolly, N., Baccari, C. \& Mortimer, R., 2000. Impact of yeast breeding for elevated glycerol production on fermentative activity and metabolite formation in Chardonnay wine. S. Afr. J. Enol. Vitic. 21, 92-99.

Pronk, J.T., Steensma, H.Y. \& Van Dijken, J.P., 1996. Pyruvate metabolism in Saccharomyces cerevisiae. Yeast 12, 1607-1633.

Puig, S. \& Perez, J.E., 2000. Stress response and expression patterns in wine fermentations of yeast genes induced at the diauxic shift. Yeast 16, 139-148.

Rankine, B.C., 1967. Influence of yeast strain and $\mathrm{pH}$ on pyruvic acid content of wines. J. Sci. Food. Agric. 18, 41-44.

Rapp, A., 1998. Volatile flavour of wine: Correlation between instrumental analysis and sensory perception. Nahrung 42, 351-363.

Rehm, H.J., 1980. Industrielle Mikrobiologie. Springer Verlag, Berlin, Heidelberg, New York.

Remize, F, Andrieu, E. \& Dequin, S., 2000. Engineering of the pyruvate dehydrogenase bypass in Saccharomyces cerevisiae: Role of the cytosolic $\mathrm{Mg}(2+)$ and mitochondrial K (+) acetaldehyde dehydrogenases Ald $6 p$ and Ald $4 p$ in acetate formation during alcoholic fermentation. Appl. Environ. Microbiol. 66, 3151-3159.

Remize, F., Roustan, J.L., Sablayrolles, J.M., Barre, P. \& Dequin, S. 1999. Glycerol overproduction by engineered Saccharomyces cerevisiae wine yeast strains leads to substantial changes in by-product formation and to a stimulation of fermentation rate in stationary phase. Appl. Environ. Microbiol. 65, 143-149.

Ribéreau-Gayon, P., Dubourdieu, D., Donéche, B. \& Lonvaud, A., 2000. Handbook of Enology. Wiley \& Sons, Ltd., Chichester, England.

Ribéreau-Gayon, P., Glories, Y., Maujean, A. \& Dubourdieu, D., 2006 (2 $2^{\text {nd }}$ ed). Handbook of enology, vol 2. John Wiley \& Sons, Ltd., Chichester, England.

Ribéreau-Gayon, J., Peynaud, E. \& Lafon M., 1956. Investigations on the origin of secondary products of alcoholic fermentation. Am. J. Enol. Vitic. $7,53-61$.

Rigoulet, M., Aguilaniu, H., Averet, N., Bunoust, O., Camougrand, N., Grandier-Vazeille, X., Larsson, C., Pahlman, I.L., Manon, S. \& Gustafsson, L., 2004. Organization and regulation of the cytosolic NADH metabolism in the yeast Saccharomyces cerevisiae. Mol. Cell Biochem. 256/257, 73-81.

Robinson, J., 2006 ( $3^{\text {rd }}$ ed). The Oxford companion to wine. Oxford University Press.

Rodrigues, F., Ludovico, P. \& Leao, C., 2006. Sugar metabolism in yeasts: An overview of aerobic and anaerobic glucose catabolism. In: Garbor, P. \& Carlos, R. (eds). Biodiversity and ecophysiology of yeasts. Springer, Berlin. pp. $101-121$.

Romano, P. \& Suzzi, G., 1993. Acetoin production in Saccharomyces cerevisiae wine yeast strains. FEMS Microbiol. Lett. 108, 23-26.

Romano, P., Fiore, C., Paraggio, M., Caruso, M. \& Capece, A., 2003. Function of yeast species and strains in wine flavour. Int. J. Food. Microbiol. $86,169-180$.

Rossignol, T., Dulau, L., Julien, A. \& Blondin, B., 2003. Genome-wide monitoring of wine yeast gene expression during alcoholic fermentation. Yeast 20, 1369-1385.

Rossignol, T., Postaire, O., Stroai J. \& Blondin, B., 2006. Analysis of the genomic response of a wine yeast to rehydration and inoculation. Appl. Microbiol. Biotechnol. 71, 699-712.

Rossouw, D., Naes, T. \& Bauer, F.F., 2008. Linking gene regulation and the exo-metabolome: A comparative transcriptomics approach to identify genes that impact on the production of volatile aroma compounds in yeast. BMC Genomics 9, 530-548. 
Roustan, J.L. \& Sablayrolles, J.M., 2002. Impact of the addition of electron acceptors on the by-products of alcoholic fermentation. Enzyme Microb. Technol. 31, 142-152.

Rywińska, A., Musiał, I., Rymowicz, W., Żarowska, B. \& Boruczkowski, T., 2012. Effect of agitation and aeration on the citric acid production by Yarrowia lipolytica grown on glycerol. Prep. Biochem. Biotechnol. 42(3), 279-291.

Saa, P.A., Moenne, M.I., Pérez-Correa, J.R. \& Agosin, E., 2012. Modelling oxygen dissolution and biological uptake during pulse oxygen additions in oenological fermentations. Bioprocess. Biosyst. Eng. 35, 1167-1178.

Sakurai, A., Imai, H. \& Sakakibara, M., 1996. Effect of oxygen tension on citric acid production by surface culture. J. Ferm. Bioeng. 82(5), 519-521.

Sanborn, T., Gavin, W., Berkowitz, S., Perille, T. \& Lesch, M., 1979. Augmented conversion of aspartate and glutamate to succinate during anoxia in rabbit heart. Am. J. Physiol. 6, 535-541.

Schmidtke, L.M., Blackman, J.W., Clark, A.C. \& Grant-Preece, P., 2013. Wine metabolomics: Objective measures of sensory properties of Semillon from GC-MS profiles. J. Agric. Food. Chem. 61, 11957-11967.

Schmit, T.M., Rickard, B.J. \& Taber, J., 2013. Consumer valuation of environmentally friendly production practices in wines considering asymmetric information and sensory effects. J. Agr. Econ. 64(2), 483-504.

Servi, S., 1990. Baker's yeast as a reagent in organic synthesis. Synthesis $1,1-25$.

Son, H.S., Hwang, G.S., Kim, K.M., Kim, E.Y., Vvan den Berg, F., Park, W.M., Lee, C.H. \& Hong, Y.S., 2009. H NMR-based metabolomic approach for understanding the fermentation behaviors of wine yeast strains. Anal Chem. 81(3), 1137-1145

Songa, H. \& Lee, S.Y., 2006. Production of succinic acid by bacterial fermentation. Enzyme Microb. Technol. 39, 352-361.

Sturgeon, J.Q., Bohlscheid, J.C. \& Edwards, C.G., 2013. The effect of nitrogen source on yeast metabolism and $\mathrm{H}_{2} \mathrm{~S}$ formation. J. Wine Res. 24(3), 182-194.

Styger, G., Prior, B. \& Bauer, F.F., 2011. Wine flavour and aroma. J. Ind. Microbiol. Biotechnol. 38, 1145-1159.

Taing, O. \& Taing, K., 2007. Production of malic and succinic acids by sugar-tolerant yeast Zygosaccharomyces rouxii. Eur. Food. Res. Technol. $224,343-347$

Thoukis, G., Ueda, M. \& Wright, D., 1965. The formation of succinic acid during alcoholic fermentation. Am. J. Enol. Vitic. 16(1), 1-8.

Tita, O., Bulancea, M., Pavelescu, D. \& Martin, L., 2006. The role of the organic acids in the evolution of the wine. CHISA $2006-17$ th Int. Congr. Chem. Proc. Engineering 5, 27-31.

Torija, M., 2003. Effects of fermentation temperature on the strain population of Saccharomyces cerevisiae. Int. J. Food. Microbiol. 80(1), 47-53.

Tu, B.P., Kudlicki, A., Rowicka, M. \& McKnight, S.L., 2005. Logic of the yeast metabolic cycle: Temporal compartmentalization of cellular processes. Science 310(5751), 1152-1158.

Ugliano, M., Henschke, P.A., Herderich, M.J. \& Pretorius, I.S., 2007. Nitrogen management is critical for wine flavour and style. Aust. N.Z. Wine Ind. J. 22, 24-30.

Usseglio-Tomasset, L., 1995 (4 ${ }^{\text {th }}$ ed). Chimica Enologica. AEB, Brescia.
Van Dorsten, F.A., Grün, C.H., Van Velzen, E.J.J., Jacobs, D.M., Draijer, R. \& Van Duyhoven, J.P., 2009. The metabolic fate of red wine and grape juice polyphenols in humans assessed by metabolomics. Mol. Nutr. Food. Res. 54, 897-908.

Varela, C., Cardenas, J., Melo, F. \& Agosin, E., 2005. Quantitative analysis of wine yeast gene expression profiles under winemaking conditions. Yeast 22, 369-383.

Vilanova, M., Varela, C., Siebert, T., Pretorius, I.S. \& Henschke, P.A., 2007. Assimilable nitrogen utilisation and production of volatile and nonvolatile compounds in chemically defined medium by Saccharomyces cerevisiae wine yeasts. Appl. Microbiol. Biotechnol. 77, 145-157.

Visser, W., Scheffers, W.A., Batenburg-Van der Vegte, W.H. \& Van Dijken, J.P., 1990. Oxygen requirements of yeasts. Appl. Environ. Microbiol. 56, 3785-3792.

Volschenk, H., Van Vuuren H.J.J. \& Viljoen-Bloom, M., 2006. Malic acid in wine: Origin, function and metabolism during vinification. S. Afr. J. Enol. Vitic. 27, 123-136.

Walker, G.M., 1998 (2nd ed). Yeast: Physiology and biotechnology. John Wiley and Sons, New York

Walker, G.M. \& Stewart, G.G., 2016. Saccharomyces cerevisiae in the production of fermented beverages. Beverages 2(4), 30.

Webb, S.R. \& Lee, H., 1990. Regulation of D-xylose utilization by hexose in pentose- fermenting yeasts. Biotech. 14, 685-698.

Weeks, S.M. \& Henschke, P.A., 2013. Yeast assimilable nitrogen. The Australian Wine Research Institute (AWRI) [Online]: https://www awri.com.au/commercial_services/analytical_services/analyses/yeast assimilable_nitrogen/yeast-assimilable-nitrogen-3/ [accessed on $31 \mathrm{March}$ 2013].

Wells, A. \& Osborne, J.P., 2012. Impact of acetaldehyde- and pyruvic acidbound sulphur dioxide on wine lactic acid bacteria. Lett. Appl. Microbial. 54, 187-194.

Wendisch, V.F., 2006. Genetic regulation of Corynebacterium glutamicum metabolism. J. Microbiol. Biotechnol. 16, 896-999.

West, E.M. \& Mauer, J.L., 2011. Development of an integrated approach for the stability testing of flavonoids and ascorbic acid in powders. Food. Chem. 129, 51-58.

Yabaya, A., Bobai, M. \& Adebayo, L.R., 2016. Production of wine from fermentation of Vitis vinifera (grape) juice using Saccharomyces cerevisiae strain isolated from palm wine. Int. J. Inf. Res. Rev. 3(10), 2834-2840.

Yang, F., Heit, C. \& Inglis, D.L., 2017. Cytosolic redox status of wine yeast (Saccharomyces cerevisiae) under hyperosmotic stress during icewine fermentation. Fermentation 3(4), 61.

Yigitoglu, M., 1992. Production of citric acid by fungi. J. Islam. Acad. Sci. 5(2), 100-106.

Zhu, Y., Eiteman, M.A., Altman, R. \& Altman, E., 2008. High glycolytic flux improves pyruvate production by a metabolically engineered Escherichia coli strain. Appl. Environ. Microbiol. 74(21), 6649-6655.

Zoecklein, B.W., 1998. Nitrogen compounds. Vintner's Corner, Virginia Tech University Enology Notes No. 13.

Zuzuarregui, A., Monteoliva, L., Gil, C. \& Del Olmo, M.I., 2006. Transcriptomic and proteomic approach for understanding the molecular basis of adaptation of Saccharomyces cerevisiae to wine fermentation. Appl. Environ. Microbiol. 72(1), 836-847. 